\title{
Assessment of the Distribution Effectiveness of Labor Protective Articles in Power Supply Enterprises based on Certain Distribution System
}

\author{
Sen $\mathrm{Liu}^{1}$, Baoyu Zhu ${ }^{1}$, Hongyan $\mathrm{Li}^{1 *}$, Yang $\mathrm{Gao}^{1}$, Hualei $\mathrm{Xu}^{1}$, Chang $\mathrm{Su}^{2}$, Zhi $\mathrm{Li}^{2}$ \\ ${ }^{1}$ State Grid Jilin Electric Power Research Institute, Changchun, Jilin Province, 130021, China \\ ${ }^{2}$ Jilin Jihan Engineering Consulting Co., Ltd, Changchun, Jilin Province, 130000, China
}

\begin{abstract}
To further optimize the distribution of labor protective articles in certain power supply enterprise, a distribution system is established to help their type selection and allocation, and questionnaires are utilized to assess the changes in relevant knowledge, behaviors, and satisfaction among the randomly sampled respondents, and the effectiveness of the distribution arising from the adoption of the system. It is demonstrated that a remarkable increase occurs in the accuracy of employees mastering knowledge pertaining to labor protective articles, and particularly their willingness to actively learn the correct method of using the articles stands at as high as $94.7 \%$; their satisfaction with the replacement cycle of the protective articles decreases, satisfaction with to what extent their requirements of protection are met by the articles distributed through the system significantly rises, and the proportion of the negative options in terms of willingness to wear the articles drops from $2.7 \%$ before adopting the distribution system to $0 \%$. It is suggested that the employees' requirements of the effectiveness and usability of the protective articles in power supply enterprises can be met quite well through this distribution system, which is of significance in providing guidance about how to enhance the practicability of such articles.
\end{abstract}

\section{Introduction}

Labor protective articles are individual gears that employers equip their laborers with in order to avoid or alleviate the harm arising from accidents and occupational diseases and maintain the safety and health in the process of production. They serve as the last ditch established for the sake of workers' safety and health ${ }^{[1,2]}$. As occupational health supervision in enterprises is confronted with increasing external pressure, it is imperative to eliminate the potential risks of occupational disease attack and urgent to carry out research on techniques pertaining to the scientific and reasonable selection of labor protective articles which function as the last ditch safeguarding the health of operation personnel. Within a power supply enterprise, job contents among different positions apparently vary, working areas contain plateaus, deserts, grassland, mountainous regions whose environmental conditions remain miscellaneous, and hazardous factors that operation personnel are exposed to also differ in category and intensity. There is a lack of targeted technical support during specifically selecting the model and identify the efficacy of labor protective articles, and a shortage of practice guidance of how frontline workers should scientifically and reasonably choose effective protective articles for themselves in accordance with the characteristics of occupational health in specific working environment. Consequently, the differentiated demands of employees in power supply enterprises for protective articles fail to be satisfied in line with different occupational health characteristics, while insufficient reference during managing the distribution of protective articles not only lessens the effectiveness of protection but wastes the expenditure of occupational health management to a certain extent.

\section{Objects and Methods}

\subsection{Objects}

This research selects two power supply enterprises in Jilin Province that operate in the city proper and forest region respectively. Labor protective articles along with questionnaires are dispensed through certain distribution system to the 80 operation personnel who are randomly drawn from typical positions according to the proportion of workers in each post before collecting and organizing the respondents' basic information and satisfaction with the distribution of protective articles, the effectiveness, practicability, and other relevant information. The positions of respondents are composed of four categories, namely oil test, power distribution in urban areas, operations and maintenance of power transmission as well as power transformation. 


\subsection{Methods}

2.2.1.Survey methods. Questionnaires are utilized to help assess the effectiveness of distributing labor protective articles with and without adopting the distribution system respectively, and to acquire an overall understanding of the respondents' basic information and satisfaction with the distribution of protective articles, the efficacy, practicability, and other relevant information. Electronic questionnaires are filled in by a certain number of frontline workers that are randomly drawn from different positions to ensure the comprehensive coverage. Labor protective articles in the same region are distributed identically and in compliance with relevant requirements of original distribution standards in this power supply enterprise. Accordingly, the respondents remain consistent.

2.2.2.Distribution of labor protective articles. The major protective articles for the aforesaid positions studied in this research was selected and distributed by means of certain distribution system in June 2020, prior to which on-site training in expertise concerning these articles had been held once. Subsequently, relevant information can be accessed by users at any time through technical specifications, knowledge training, and video tutorials of such distribution system. Post-evaluation of the same group of respondents was conducted by using questionnaires in September 2020, three months after the distribution of the protective articles. Questions designed for the protective effect of and satisfaction with such articles are basically identical.

\subsection{Statistical analysis}

Questionnaires are designed by using the online platform called Wenjuanxing, and distributed to respondents by means of online participation via WeChat. SPSS 23.0 is the very software that is used for data analysis in this research. Technical data are expressed as absolute numbers and percentages, statistical inferences are tested by using $\chi^{2}$, and, in all tests, difference that appears statistically significant is represented as $\mathrm{P}<0.05$.

\section{Results}

\subsection{Basic information}

Respondents participating in the survey total 160, while among the collected questionnaires 152 are valid. All the differences in the gender, age and working years of the respondents are not statistically significant $(\mathrm{P}>0.05)$ (see Table 1).

Table 1 Basic information characteristics of research object

\begin{tabular}{|c|c|c|c|c|c|c|}
\hline \multirow{2}{*}{ project } & \multicolumn{2}{|c|}{ Preliminary basic information } & \multicolumn{2}{|c|}{$\begin{array}{c}\text { Evaluation result after } \\
\text { equipped }\end{array}$} & \multirow{2}{*}{$\chi^{2}$} & \multirow{2}{*}{$\mathbf{P}$} \\
\hline & number & $\begin{array}{l}\text { Proportion } \\
(\%)\end{array}$ & number & $\begin{array}{l}\text { Proportion } \\
(\%)\end{array}$ & & \\
\hline \multicolumn{7}{|l|}{ Post } \\
\hline $\begin{array}{c}\text { Substation operation and } \\
\text { maintenance }\end{array}$ & 50 & 32.9 & 38 & 25.0 & 32.38 & $<0.05$ \\
\hline Urban distribution & 28 & 18.4 & 16 & 10.5 & & \\
\hline $\begin{array}{l}\text { Transmission operation and } \\
\text { maintenance }\end{array}$ & 70 & 46.1 & 95 & 62.5 & & \\
\hline Oils test & 4 & 2.6 & 3 & 2.0 & & \\
\hline $\begin{array}{c}\text { Sex } \\
\text { male } \\
\text { female }\end{array}$ & $\begin{array}{c}148 \\
4\end{array}$ & $\begin{array}{c}97.4 \\
2.6 \\
\end{array}$ & $\begin{array}{c}150 \\
2\end{array}$ & $\begin{array}{c}98.7 \\
1.3 \\
\end{array}$ & 0.055 & 0.815 \\
\hline \multicolumn{7}{|l|}{ Age } \\
\hline$\leqq 20$ & 1 & 0.7 & 0 & 0 & 13.76 & 0.316 \\
\hline $21-30$ & 38 & 25.0 & 33 & 21.7 & & \\
\hline $31-40$ & 59 & 38.8 & 63 & 41.4 & & \\
\hline $41-50$ & 34 & 22.4 & 27 & 17.8 & & \\
\hline$>51$ & 20 & 13.2 & 29 & 19.1 & & \\
\hline \multicolumn{7}{|l|}{ Working age } \\
\hline $11-15$ & 30 & 19.7 & 41 & 27.0 & 15.32 & 0.502 \\
\hline $16-20$ & 14 & 9.2 & 18 & 11.8 & & \\
\hline$>20$ & 40 & 26.3 & 48 & 31.6 & & \\
\hline$\leq 5$ & 38 & 25.0 & 23 & 15.1 & & \\
\hline $6-10$ & 30 & 19.7 & 22 & 14.5 & & \\
\hline
\end{tabular}

\subsection{Changes arising from certain distribution system in knowledge and behaviors relevant to labor protective articles among the employees}

Table 2 presents the changes in knowledge and behaviors relevant to labor protective articles among the employees before and after adopting certain distribution system. The rate of correctly perceving the exposure to occupational disease factors increases from $69.1 \%$ before the adoption of the distribution system to $79.6 \%$; the rate of mastering the proper wearing methods of protective articles rises from $57.9 \%$ to $76.3 \%$; the willingness to actively learn the correct method of using such articles goes up from $87.5 \%$ to $94.7 \%$; the rate of properly placing and safekeeping such articles increases from $62.5 \%$ to $80.9 \%$; the rate of replacing them within proper period rises from $42.8 \%$ to $64.5 \%$. 
Table 2 Changes in knowledge and behaviors relevant to labor protective articles among the employees before and after adopting certain distribution system[N(i/\%)]

\begin{tabular}{|c|c|c|c|c|c|c|c|c|c|c|}
\hline \multirow[b]{2}{*}{$\begin{array}{l}\text { knowledge } \\
\text { and } \\
\text { behaviors }\end{array}$} & \multicolumn{5}{|c|}{ Preliminary basic information } & \multicolumn{5}{|c|}{ Evaluation result after equipped } \\
\hline & $\begin{array}{c}\text { Substation } \\
\text { operation and } \\
\text { maintenance }\end{array}$ & $\begin{array}{c}\text { Urban } \\
\text { distributi } \\
\text { on }\end{array}$ & $\begin{array}{c}\text { Transmission } \\
\text { operation and } \\
\text { maintenance }\end{array}$ & Oils test & total & $\begin{array}{c}\text { Substation } \\
\text { operation and } \\
\text { maintenance }\end{array}$ & $\begin{array}{c}\text { Urban } \\
\text { distributi } \\
\text { on }\end{array}$ & $\begin{array}{c}\text { Transmission } \\
\text { operation and } \\
\text { maintenance }\end{array}$ & $\begin{array}{l}\text { Oils } \\
\text { test }\end{array}$ & total \\
\hline $\begin{array}{c}\text { Correct } \\
\text { understanding } \\
\text { of } \\
\text { occupational } \\
\text { hazards }\end{array}$ & $26(52.0)$ & $19(67.9)$ & $57(81.4)$ & $3(75.0)$ & $105(69.1)$ & $28(73.7)$ & $12(75.0)$ & $78(82.1)$ & $3(100)$ & $121(79.6)$ \\
\hline $\begin{array}{l}\text { Correct ways } \\
\text { to wear labor } \\
\text { protect } \\
\text { equipment }\end{array}$ & $23(46.0)$ & $17(60.7)$ & $46(65.7)$ & $2(50)$ & $88(57.9)$ & $29(76.3)$ & $12(75.0)$ & $72(75.8)$ & $3(100)$ & $116(76.3)$ \\
\hline $\begin{array}{l}\text { Actively } \\
\text { master the } \\
\text { Correct ways } \\
\text { to wear labor } \\
\text { protect } \\
\text { equipment }\end{array}$ & $42(84.0)$ & $23(82.1)$ & 64(91.4) & $4(100)$ & $133(87.5)$ & $35(92.1)$ & $14(87.5)$ & $92(96.8)$ & $3(100)$ & $144(94.7)$ \\
\hline $\begin{array}{l}\text { Behavior of } \\
\text { keeping labor } \\
\text { protect } \\
\text { equipment } \\
\text { correctly }\end{array}$ & $22(44.0)$ & $17(60.7)$ & $53(75.7)$ & $3(75.0)$ & $95(62.5)$ & $29(76.3)$ & $12(75.0)$ & $79(83.2)$ & $3(100)$ & $123(80.9)$ \\
\hline $\begin{array}{l}\text { Correct } \\
\text { choice for } \\
\text { replacing } \\
\text { labor protect } \\
\text { equipment } \\
\end{array}$ & $24(48.0)$ & $24(42.9)$ & $24(40.0)$ & $24(25.0)$ & $24(42.8)$ & $23(60.5)$ & $10(62.5)$ & $63(66.3)$ & $2(66.7)$ & $98(64.5)$ \\
\hline
\end{tabular}

\subsection{Changes arising from certain distribution system in degree of satisfaction with labor protective articles among the employees}

\subsubsection{Changes in satisfaction with the replacement cycle of labor protective articles among the} employees. Figure 1 shows the distribution of the employees' satisfaction with the replacement cycle of labor protective articles before and after adopting certain distribution system. The proportion of the positive options "totally agree" and "agree" exceeds $82 \%$ both before and after the distribution system is adopted; the proportion of the negative options "disagree" and "strongly disagree" totals $6.6 \%$ before adopting the distribution system, which increases to $7.9 \%$ after adopting the system. It is indicated that the degree of satisfaction with the replacement cycle of the protective articles among the employees declines after adopting the distribution system.

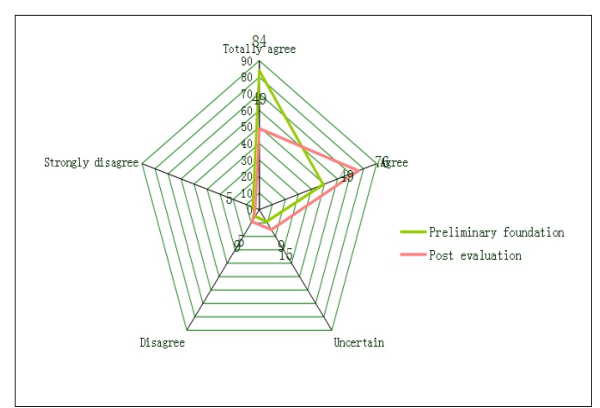

Fig.1 Distribution of satisfaction on replacement cycle

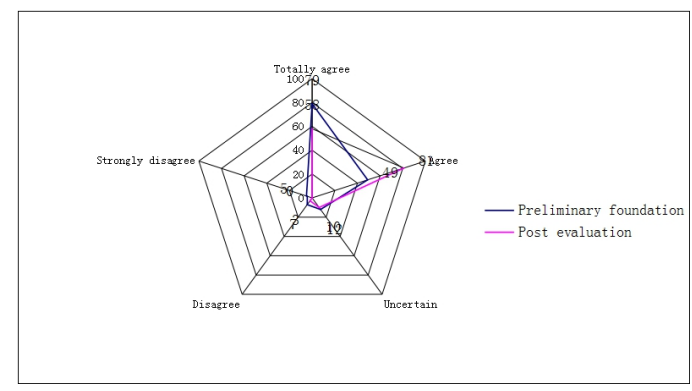

Fig.2 Distribution of satisfaction on protection need

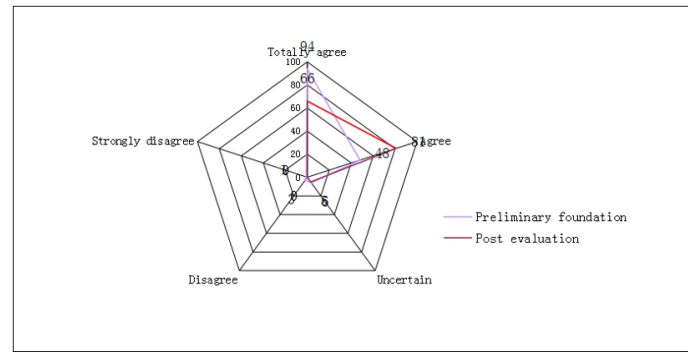

Fig.3 Distribution of satisfaction on wearing intention

3.3.2. Changes in satisfaction with whether the labor protective articles meet the requirements of protection.. Figure 2 displays the distribution of the employees' satisfaction with whether the labor protective articles can meet the requirements of protection before and after adopting the distribution system. The total proportion of the positive options "totally agree" and "agree" rises from $84.2 \%$ to $88.5 \%$ after adopting the system, while the total proportion of the negative options "disagree" and "strongly disagree" drops from $7.9 \%$ to $2 \%$. It is implied that the protective articles distributed through the system can satisfy employees' requirements of protection in each position better. In particular, the significant decrease in the proportion of negative options pertaining to the position of power distribution in urban areas and operations and 
maintenance of power transformation demonstrates that the effectiveness and usability of this distribution system can meet the employees' needs very well.

\subsubsection{Changes in willingness to wear the distributed labor protective articles among the employees.} Figure 3 shows the distribution of the employees' willingness to wear the distributed labor protective articles in their work process before and after adopting the distribution system. The total proportion of the positive options "totally agree" and "agree" rises from $93.4 \%$ to $96.7 \%$ after adopting the system, while the total proportion of the negative options "disagree" and "strongly disagree" drops from $2.7 \%$ to $0 \%$, which proves the practicability of the labor protective articles distributed through the system and the remarkable change in employees' willingness. This distribution system can make a difference in terms of the practicability of the protective articles.

\section{Discussion}

The distribution system makes information pertaining to labor protective articles conveniently available to the employees, enhances their willingness to actively learn the correct method of using the articles, and provides them with guidance about utilizing the articles correctly. With regard to the employees' knowledge and behaviors concerning labor protective articles after adopting the distribution system, the rate of correctly choosing the replacement cycle increases by $21.7 \%$, showing the most significant change, which, however, appears still relatively low since what most employees choose in terms of the replacement cycle of the protective articles turns out to be "unified replacement by the employers", the most influential way, instead of the correct option "replace when the requirements of protection fail to be met". The employees' willingness to actively learn the correct method of using the articles shows the smallest change, simply increasing by $7.2 \%$. The reason is that original degree of willingness already stands at as high as $87.5 \%$, which rises to $94.7 \%$ after adopting the distribution system, indicating that the employees in the power supply enterprises possess strong willingness to actively master the right way of using the articles all the time and have developed good habits.

In terms of the employees' satisfaction with the replacement cycle of the protective articles, the increase in the proportion of negative options after adopting the distribution system is principally due to the cancellation of previous excess and advance distribution in some positions that are replaced by the sophisticated and reasonable distribution mode through the system in accordance with the actual intensity of hazards in specific working areas and occupational hazard characteristics of each position ${ }^{[3]}$, which causes the decrease in the degree of satisfaction with this aspect among some employees. Nevertheless, field survey demonstrates that operation personnel in most positions agree that the distribution cycle of labor protective articles through the system is reasonable and their operational requirements can be satisfied. It is suggested that the employees' demands are satisfied after the adoption of the distribution system, and meanwhile the expenditures incurred in the distribution is reduced to a certain extent, which is favorable for the enterprises to better manage their expenses.

In summary, the adoption of the distribution system significantly influences the usability and practicability of the distribution of labor protective articles in power supply enterprises, and appears beneficial to the increase in economic benefits and, in particular, to the improvement of the employees' knowledge and behaviors concerning labor protective articles. This distribution system optimizes the management system of procurement, acceptance check, storage, allotment, use and discarding of such articles that power supply enterprises should establish and perfect, and meets the practical demands of urging and educating workers to properly wear and use the articles ${ }^{[4]}$, which plays an essential role in safeguarding the life and health of the employees and enhancing labor protection in the electric power industry ${ }^{[5]}$.

\section{Acknowledgments}

This work was financially supported by science and technology project of Grid Corporation of China 522300180004 fund.

\section{References}

1. Xurong Liu. (2009) The development trend of personal protective equipment in China. J. China Personal Protective Equipment, 01: 6-7.

2. (2019) Pay attention to personal protective equipment. J. Labour Protect, 07:10-11.

3. Sen Liu, Chengxun Sun, Yang Gao(2020) Suggestions on labor protective equipment-A preliminary introduction. J. Labor Security World, 09:38.

4. Wenfen Yang.(2020)Personal protective equipment shall be provided for compliance. J. China Personal Protective Equipment, Z1: 11-13.

5. Hailei Jiang, Changhong Li.(2018)Research on the problems of personal protective equipment in power industry. J. Labor Security World,14:43-44. 